\title{
e-Imigrações como um work in progress
}

\author{
Alckmar Luiz dos Santos (UFSC) ${ }^{1}$ \\ Rafael Duarte (UFSC) ${ }^{2}$ \\ Vinícius Rutes Henning (UFSC) ${ }^{3}$
}

\section{Introdução}

A CRIAÇÃO LITERÁRIA DIGITAL E-IMIGRAÇÕES ${ }^{4}$ ASSOCIA TRÊS LINGUAGENS: AS HISTÓRIAS-EM-QUADRINHOS ${ }^{5}$ (OU SEJA, SUas estratégias visuais e narrativas), a poesia (especificamente o ritmo verbal e imagético dos versos) e a programação computacional (no que ela traz de interatividade e de imersividade). O que essa obra apresenta a seus leitores é a dimensão humana trágica dos deslocamentos migratórios contemporâneos, causados por catástrofes coletivas, como o terremoto no Haiti, a guerra civil na Síria e a crise político-econômica na Venezuela. A partir de narrativas ficcionais envolvendo imigrantes desses três países que vêm para o Brasil, quisemos mostrar como e por que abandonam seus lares e como se dá o deslocamento até aqui, sem deixar de mencionar as dificuldades que vêm enfrentar no novo país. É claro que a ficcionalização é uma estratégia para ampliar o efeito artístico na apresentação de graves mazelas contemporâneas, afastando o risco de cairmos em atitude panfletária que seria mais produtiva num escrito ideológico e não em uma obra de arte. O que nos inspira, no caso, é sempre a reflexão que Eça de Queirós coloca como epígrafe de seu belíssimo romance, A relíquia: "Sobre a nudez forte da verdade - o manto diáfano da fantasia."

A ideia base para a criação do que se tornou, ao final do processo, a obra intitulada e-Imigrações, surgiu das discussões ocorridas entre seus três criadores ${ }^{6}$ sobre as aproximações possíveis entre gêneros que utilizam, de alguma maneira, a espacialidade como elemento constitutivo, como pode ser o caso do poema verbal, como é certamente o da poesia visual e o das HQ's, tudo associado de forma coerente no todo da criação digital. Há nela três partes, correspondentes a cada um dos países acima citados, abordando a tragédia específica de cada região, mas partindo do que viram e viveram indivíduos. De certa forma, buscamos estabelecer uma relação de analogia entre esses indivíduos ficcionais criados na narrativa de e-Imigrações e a tragédia nada ficcional que acometeu esses três países. Contudo, entre a individualidade fictícia e a generalidade concreta da história fica aberto o espaço para a fantasia dos criadores e dos leitores. É justamente esse "manto diáfano" da fantasia que permite a estes últimos viver profundamente, sem necessidade da mediação ideológica ou da reflexão intelectual, uma tragédia que, até o momento da leitura, ainda não era deles leitores.

\footnotetext{
${ }^{1}$ Professor-titular de Literatura Brasileira da Universidade Federal de Santa Catarina, pesquisador do CNPq, coordenador do Núcleo de Pesquisas em Informática, Literatura e Linguística (NuPILL).

${ }^{2}$ Doutor em Literaturas pela Universidade Federal de Santa Catarina, pesquisador do NuPILL.

${ }^{3}$ Graduando em Letras na Universidade Federal de Santa Catarina, membro do NuPILL.

${ }^{4}$ Disponível no endereço eletrônico: www.editorainverso.com.br/livro-digital

${ }^{5}$ Doravante, HQ's.

${ }^{6}$ E também autores deste trabalho. Criação realizada no âmbito do Núcleo de Pesquisas em Informática, Literatura e Linguística - NuPILL, disponível em https://www.nupill.ufsc.br. Acesso em 27/06/2021.
} 


\section{Processos criativos}

É possível apontar e comentar alguns pontos importantes no processo criativo de e-Imigrações, a partir das discussões realizadas por seus criadores, por meio de dois documentos colaborativos que reúnem tanto anotações individuais quanto resumos dos encontros presenciais de discussão e, propriamente, de criação. Disponíveis no Google Drive apenas para os três artistas envolvidos na criação, esses documentos são chamados, respectivamente: CRIAÇÃO DIGITAL-página infinita, em que discutimos os elementos constitucionais da criação e suas possíveis estrateǵias narrativas e composicionais, além de colocar todos os poemas escritos para a obra em si; Caminhos curtos mais longos, em que foram escritos, discutidos e reelaborados os roteiros de cada uma das histórias, além de servir de espaço para armazenar e expor algumas referências visuais e sonoras para os elementos gráficos e musicais da criação. No caso, cumpre esclarecer que, além dos três principais criadores, e-Imigrações envolveu artistas gráficos (Samuel Casal, Allisson Affonso, Otávio Bittencourt) e um compositor (Daniel Duarte).

A seguir, iremos apresentar e discutir brevemente alguns dos pontos retirados desses documentos, especificamente aqueles que julgamos mais importantes para dar a nossos leitores uma visão mais clara de como foram as etapas iniciais de nosso processo criativo. Trata-se, com efeito, de uma tentativa nossa de mostrar o lado de cá do processo criativo, estes bastidores que, quase sempre, são escondidos do olhar por vezes intensamente voyeur do leitor.

\section{1 - Ideias iniciais}

O primeiro impulso para a criação de e-Imigrações surgiu nas discussões sobre literaturas digitais ocorridas no Núcleo de Pesquisas em Informática Literatura e Linguística (Nupill), especificamente naquelas que se debruçaram sobre o uso de elementos verbo-visuais analógicos (ou seja, não digitais) em criações digitais. A mais profícua dessas características e que acabou se tornando um eixo estruturador da criação como um todo, foi a diferença entre o uso do espaço em um meio textual analógico e o meio digital, mais especificamente a possibilidade de criação de uma página virtualmente infinita ${ }^{7}$. Não é demais salientar que se trata de espaços textuais impossíveis no meio analógico. A partir daí foram discutidas possibilidades de criação fazendo uso de gêneros textuais que utilizam mais explicitamente a espacialidade como elemento constitutivo, a exemplo do poema, da poesia visual e das histórias-em-quadrinhos. Definidas essas escolhas, tornava-se necessário um assunto que conseguisse congregar as particularidades dos gêneros textuais e o uso estético do espaço, o que foi resolvido como se pode acompanhar seguindo o excerto abaixo:

Olá, pessoal. Compartilho aqui uma ideia que tive para utilizar na criação do poema visual digital, que também se encaixa na ideia do III Simposio de la Sección de Estudios del Cono Sur (LASA) 2019.

Para isso, no entanto, preciso contar algo que aconteceu esses dias. Estava com meus filhos no lado do shopping Iguatemi (fugindo da chuva) e ouvi um senhor que trabalhava na faxina do shopping conversando com uma mulher (que também trabalhava no shopping). Ele era do Haiti e pelo que contou, tinha graduação (não consegui ouvir em quê) e trabalhava nela. Quando aconteceu o terremoto que arrasou com o Haiti, ele perdeu tudo e teve que vir para o Brasil, onde trabalha recolhendo lixo no shopping.

Lembrei na hora de uma tirinha da Laerte feita na época do terremoto, que também analisei na tese (segue anexo). Pensei que tratar sobre uma situação análoga seria uma maneira de tratar tanto sobre o tema do simpósio ("obras/piezas/proyectos del cono sur que trabajan con diversos tipos de desplazamientos/migraciones"), quanto com um questão que lida com diferentes ideias de espacialidade (o lugar original, o terremoto, o deslocamento, o novo lugar) e também lidar com essa onda de xenofobia

\footnotetext{
${ }^{7}$ Discussão iniciada em DUARTE, Rafael Soares. “A página infinita: leitura de algumas possibilidades narrativas nas Webcomics”. In: FreitAs, Deise J. T. de; DuARTE, Rafael Soares [org.].Literaturas entre o digital e o analógico. Teresina: Edufpi, 2013, pp.29-39.
} 
no país feito de imigrantes. É só uma ideia, e depende de nosso escriba-mor achar que isso dá algum caldo. Vou colar o que escrevi num documento do google docs que já envio também.

A situação dos refugiados conseguiu, assim, reunir o polo temático e a poiesis que ora se discutia, por associar justamente uma dimensão humana à espacialidade, já que esta se fundava, então, no processo de deslocamento dos refugiados de seus países de origem até o Brasil.

Tendo entendido o escopo inicial da obra, antes de nos aprofundarmos nas suas especificidades, é interessante trazer uma perspectiva mais ampla sobre Literatura Digital. Exploramos em um outro estudo ${ }^{8}$ a estrutura básica de obras literárias digitais e, com base nessa análise, é possível entender uma obra literária digital a partir de 3 componentes essenciais: o verbo-literário, o computacional e o semiótico. Todos os elementos e estratégias literárias (como figuras de estilo e recursos sintáticos) se consolidam no componente verbo-literário. Já no computacional encontram-se todas as lógicas de imersão e interatividade possibilitadas pelo meio digital, que extrapolam as estratégias da literatura impressa. Por fim, no componente semiótico encontramos tudo que diz respeito a movimento, som, imagem, etc.

Com essa divisão é possível entender, por exemplo, que as criações literárias tradicionais se importam apenas com o componente verbo-literário, enquanto que podem existir softwares e vídeos com elementos semióticos e computacionais, mas que não trazem matéria verbal. No entanto, é na junção desses três eixos (sem que se reduzam a um único) que encontramos o objeto literário digital pleno, resultado da hibridização de estratégias distintas de produção de sentidos, o que e-Imigrações pretendeu ser desde o início.

\section{2 - Primeira imagem}
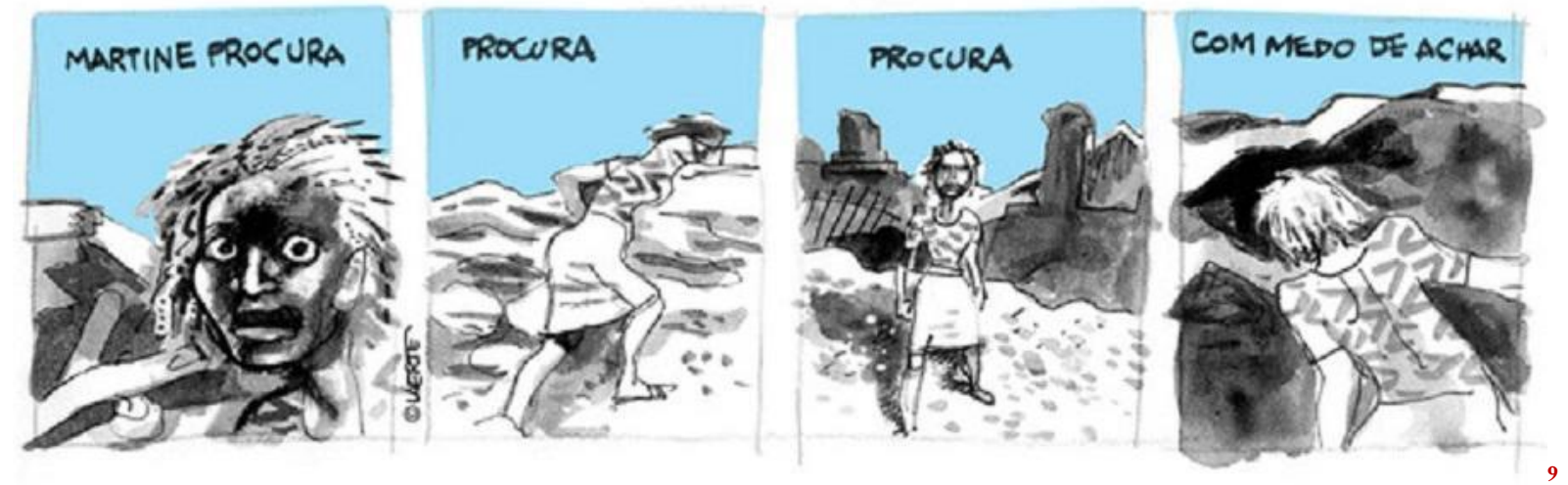

\footnotetext{
${ }^{8}$ LUIZ DOS SANTOS, Alckmar. Quelques questions concernant les genres, à partir de l'actuelle littérature numérique brésilienne. In: TOMICHE, Anne. Le Comparatisme comme approche critique Comparative Literature as a Critical Approach. Littérature, science, savoirs et technologie / Literature, Knowledge, Science and Technology. Tomo 6. Paris: Garnier, 2017, pp. 331 -345.

${ }^{9}$ Disponível em http://verbeat.org/laerte/haiti. Acesso em 29/06/2021.
} 
Tanto o encontro com o trabalhador haitiano, quanto a tira da cartunista Laerte apontaram para a escolha do Haiti como país a ser escolhido para entrar na criação. Na sequência, outros dois (Síria e Venezuela) foram incorporados, mas é importante salientar que, nos três casos, partimos dessa busca pelo outro que é também a busca por si mesmo, em qualquer um dos três países, com quaisquer dos personagens que fomos criando. Isso, aliás, levou ao primeiro título (provisório, evidentemente) que pensamos para a criação.

\section{3 - Primeiro título}

\begin{tabular}{lllll} 
& OUTRO & \multicolumn{2}{c}{ MESMO } & \\
SER & & EM & LUGAR \\
& OMESMO & & OUTRO &
\end{tabular}

[documento CRIAÇÃO DIGITAL - página infinita]

Tratava-se mais de uma articulação semântica do que propriamente de um título. Rapidamente percebemos que esse era um dos eixos da criação, senão o eixo mais importante: a hesitação entre ser o mesmo e tornar-se outro, a oscilação entre o aqui e o acolá, ambas as disjunções interferindo uma na outra, produzindo quatro combinações possíveis. Ademais, esse mecanismo deveria estar em todos os níveis da criação: nas interações e imersões digitais, nas imagens poéticas trazidas nos versos, nos ritmos (sejam os da leitura, sejam os da trilha sonora), nas justaposições de imagens seguindo a lógica das HQ’s...

\section{4- Referências iniciais}

De certo modo, as lógicas digitais, expressas nas estratégias de imersão e de interatividade, foram elaboradas inicialmente a partir das lógicas imagéticas dos quadrinhos. Mas, tomadas isoladamente, estas últimas não seriam suficientes, pois havia ainda que associar a elas uma dimensão literária que permitisse desenvolver narrativas e personagens para os três países. Daí surgiu a primeira influência buscada por nós, a HQ Maus $^{10}$, em que uma metáfora visual (a dos judeus retratados como camundongos) é retirada justamente de uma obra literária, o conto “Josefina, a cantora, ou O povo dos camundongos” do também judeu Franz Kafka.

\footnotetext{
\# Acho que uma referência interessante seria o Maus, do Art Spiegelman

\# A ideia é usar algo da visualidade das HQ's? (se for o caso, temos que ver a questão de como isso ficaria "desenhisticamente", talvez em uma só parte, ou em momentos predefinidos)

\# Formas visuais ligadas à poesia visual moderna
}

[documento CRIAÇÃO DIGITAL - página infinita]

\footnotetext{
${ }^{10}$ Spiegelman, Art. “Maus”. Raw Magazine. New York: Penguim Books, 1980-1991.
} 
Ora, essa específica referência literária (o conto do escritor tcheco) baseia-se numa metáfora. Em outras palavras, é uma imagem virtual que foi concretizada diretamente por Art Spiegelman em sua HQ ao desenhar seus personagens como ratinhos de aparência humanizada. No caso da nossa criação, interessava-nos, mais do que mera recriação visual da metáfora como fez Spiegelman, a lógica visual de construção dos significantes, vale dizer, dos componentes semióticos de nossa criação. No caso, serviu de orientação o trabalho de Rafael Duarte sobre os diálogos entre poesia visual e HQ's ${ }^{11}$. Em outras palavras, as técnicas da poesia visual, desde o início, foram tomadas como método para nossa criação literária digital, através desse diálogo com as HQ’s, mas trazendo para os dias de hoje, na prática, o que Rafael apresentou e discutiu com relação à poesia visual moderna, de fins do século XIX até metade do século XX.

\section{5 - Etapas das narrativas, definições de paises e roteiro}

O que se pensou especificamente para o Haiti, isto é, para os microenredos e para os personagens, foi também realizado pouco mais tarde para os casos de Síria e de Venezuela. Pode-se dizer que se buscou, desde o início, uma rigorosa homologia entre os países, em tudo que aparece deles em e-Imigrações. Não poderia ser diferente para os elementos narrativos. No caso do Haiti, aparece a seguir o que foi planejado ao início, chamando a atenção para dois termos: transição e ruptura.
\# Ruptura cultural e geológica (transição de "gênero")
\# Transição de escrita (mudança de fonte) (forma de pensar a quebra de entendimento no novo país? em algum momento do deslocamento também?)
\# Haikus + Versos quebrados + Poema longo metaforizando o percurso
\# Dois (três) momentos separados: Haiti (deslocamento) e Brasil
\# Haiti: história (expandir os quadrinhos que contam a história), vida antes do terremoto, terremoto
\# Saída: deslocamento, percurso do refugiado, apátrida
\# Brasil: violência, assassinato, reconstrução (solidariedade?), haitiano já aqui mas com família lá?
\# Sobre o ponto de vista do Brasil, poderíamos ter alguma parte com um eu-lírico diferente, vendo a partir do Brasil
\# Outra possibilidade é o ponto de vista de diferentes eus-líricos, diferentes vidas, haitianos e brasileiros, além daquela passagem de tempo sobre a qual falamos, como em "Concierto Barroco" de Alejo Carpentier, que possibilita falarmos um pouco da história do país

[documento CRIAÇÃO DIGITAL - página infinita]

Nesse caso, ao trabalhar a seguir com Síria e Venezuela, tratamos apenas de alterar os elementos narrativos associados à transição e ruptura. No caso desta segunda, o que era geológico no primeiro (no Haiti, o terremoto) tornou-se, na Síria, ruptura política pela militarização de diferentes grupos; no que se refere à Venezuela, a ruptura vem atingir a sociedade como um todo,

${ }^{11}$ DuARTE, Rafael Soares. Aproximações entre poesia visual moderna e histórias em quadrinhos. Tese de doutoramento. Florianópolis: Programa de Pós-graduação em Literatura, Universidade Federal de Santa Catarina, 2016. Disponível em https://repositorio.ufsc.br/xmlui/handle/123456789/169210. Acesso em 29/04/2021. 
mas mais duramente as camadas empobrecidas, aprofundando o fosso entre as classes econômicas. Não havendo, nos três países, perspectivas de transição para uma situação melhor, esta (a transição) se torna emigração. Assim, se há elementos e causalidades narrativas distintas, as mesmas técnicas de composição da criação verbal (versos e poemas curtos revezando com versos e poemas longos), para os três países, aponta para um campo comum entre as três tragédias: a ruptura que leva à transição, isto é, à tentativa de fuga do sofrimento que, sem que o saibam os personagens, acaba levando a mais e a outros sofrimentos. Assim, a homologia a que nos referimos acima também aparece na mesma sequência narrativa que se desenvolve nos três espaços geográficos: tragédia, deslocamento geográfico, nova vida no Brasil.

Definidos os países e a sequência de eventos que iriam compor a narrativa de cada país, foi necessário particularizá-las através da criação de enredos relativos a cada situação retratada. Assim, foram realizadas pesquisas sobre as situações e dificuldades específicas relatadas por refugiados de cada um dos três países, a partir da qual foram compostas as narrativas que, embora ficcionais, foram criadas a partir da conjugação de diversas vivências reais daqueles que precisaram abandonar seus países. Em relação ao Haiti, a narrativa acompanha uma família em que quase todos os membros sobrevivem, estando em lugares diferentes no momento do terremoto. Nessa narrativa, decidimos utilizar alguns elementos de sua religiosidade tanto nos poemas quanto em alguns momentos gráficos, como o Baron Samedi. Em relação à Síria, a narrativa acompanha a história de uma família que se vê acuada por confrontos armados entre milícias e bombardeios até a fuga dos sobreviventes pelo mar sob uma perspectiva subjetiva que demonstra a monstruosidade da situação. Já a narrativa da Venezuela acompanha a trajetória de um homem que, em meio à crise econômica, perde seu emprego e família, e testemunha o assassinato de um jovem pela polícia durante um saque a um supermercado. Aqui a visão subjetiva dá suporte à uma metáfora porcina bastante conhecida, mas coerente com as visões aqui trabalhadas, sobre as figuras de autoridade. Após essas histórias, as narrativas mostram o destino de cada pessoa ou grupo no Brasil, buscando trabalho, aprendendo sobre o racismo e xenofobia e tentando se restabelecer em uma cultura diferente.

Um roteiro de HQ é um texto que pode ser configurado de diversas maneiras, variando de indicações sucintas a descrições detalhadas do cenário, das personagens, de ângulos de visibilidade, de referências, de quantidade de detalhes e mesmo do layout de página. Assim, após estabelecidas, cada trama precisou ser roteirizada em relação às particularidades gráficas e narrativas de cada artista convidado. Em relação à Síria, cuja narrativa gráfica se baseia em ilustrações realizadas em xilogravuras, os episódios narrativos precisaram ser condensados em momentos únicos, como splash page (página de ilustração única), deixando, assim, grande parte do encadeamento narrativo a cargo dos poemas. Para o Haiti, diferentemente, o layout narrativo das HQ's ganhou primazia, o que fez com que houvesse necessidade de enviar ao ilustrador um resumo narrativo de cada situação, descrevendo acontecimentos e falas que aconteceriam a cada página. No que toca à história venezuelana, como ela foi desenhada pelo próprio roteirista, o roteiro não precisou ser descrito, as indicações da história foram definidas diretamente na página. Por fim, em relação ao Brasil, foi produzido um roteiro pormenorizado, com descrições de organização de página e detalhamento sobre cada painel, sobre o qual trabalhou o ilustrador.

\section{6 - Elementos de programação}

Ao longo do processo de criação, fomos desenvolvendo estratégias para integrar as diferentes semioses (poesia, roteiro, música, quadrinhos, imagens e, é claro, programação computacional) num todo com um mínimo de coerência. O problema com várias criações literárias digitais reside justamente na falta de organicidade, isto é, no fato de cada semiose impor uma leitura 
exclusiva, independente das outras ${ }^{12}$. Ora, como em toda obra literária digital, a programação em e-Imigrações tem papel de relevo, pois é na interface de leitura produzida computacionalmente que os diferentes elementos se materializam em um objeto coeso; portanto, é imprescindível que haja uma comunhão entre o código de programação e as poiesis das artes envolvidas.

As primeiras discussões sobre imersão e interatividade já levavam em conta as estratégias de programação, ainda que isso não estivesse explícito. Sabíamos desde o início que não haveria um profissional da computação para programar e-Imigrações e, por este motivo, o software de desenvolvimento de jogos Unity acabou sendo a melhor escolha, principalmente com a utilização da ferramenta Fungus, que modifica a interface e as funcionalidades da plataforma para possibilitar o desenvolvimento sem uma linguagem de programação explícita. Naturalmente, ainda foi necessário um aprendizado sobre a interface e funcionamento do software, porém, a barreira de entrada foi significativamente reduzida considerando a nossa falta de formação na área. Em suma, a relação com o Unity/Fungus, como deve ocorrer com qualquer software utilizado em criações artísticas digitais, nunca se limitou a uma utilização pragmática, restrita a uma lógica externa à concepção artística. O que buscamos constantemente foi dialogar com o programa fora das diretrizes de manual.

De todo modo, a experimentação com a ferramenta de programação foi uma constante ao longo do desenvolvimento da obra e, nesse sentido, foi muito interessante que o responsável pela programação, Vinícius Rutes, também participasse ativamente das decisões criativas da obra, desde a sua temática até a definição de detalhes de leitura, como a escolha da velocidade de zum na transição entre imagens e poemas; a sequência aleatória, gerada automaticamente, de navegação entre partes da obra etc. Já outros detalhes, planejados numa fase inicial das discussões, não chegaram a ser implementados. Percebe-se isso no trecho em que esboçamos a primeira versão da interface principal de navegação:

\# Mapa múndi com o cursor em forma de astronauta; quando passa sobre alguns países (menos os do primeiro mundo), vem som de Serra Leoa; sobre Haiti, Venezuela e Siria, ouvem-se poemas sobre as tragédias desses países;

\# Haiti: o mapa vai se rasgando em pedaços, à moda de efeito de terremoto; cada parte vai para um lado e se torna um quadrinho e dá acesso a histórias em versos, sobre cada personagem, todos membros de uma família (dois poemas para cada um: antes e depois do terremoto);

\# Siria: Uma nuvem de gás esconde o mapa e, quando ela some, aparecem corpos espalhados e mortos e cada corpo vai se transformar num quadrinho. Neles também se contam histórias de uma mesma família.

\# Venezuela: um buraco que vai aumentando e toma todo o mapa; notas de bolivar (que não valem nada) são expelidas pelo buraco e se transformam em quadrinhos; mesma coisa que com os outros: histórias de uma família.

[documento CRIAÇÃO DIGITAL - página infinita]

O acesso principal (ou seja, a interface de entrada) à obra passou por diversas configurações, à medida que se iam construindo os enredos. Um aspecto crucial para essa decisão seria a presença ou ausência de linearidade nas histórias. Ao final, decidiu-se que a ordem de navegação seria livre entre os três países de imigrantes, mas a chegada ao Brasil ficaria necessariamente como desfecho da obra, o que representaria uma sequência parcialmente fechada. Como acima, os comentários a seguir trazem outras possibilidades que foram pensadas, mas que, ao final, não foram todas implementadas:

Estou imaginando algumas formas distintas de entrada/leitura/audição em personagens/acontecimentos/poemas:

\footnotetext{
${ }^{12}$ Um Frankenstein que não vive, para usarmos uma metáfora de fácil compreensão; ao contrário, o que sempre queremos criar é um Frankenstein que tenha vida.
} 
- ou se entra pelos personagens (haveria um quadrinho para cada personagem; de cada quadrinho, se poderia ir para o acontecimento em que ele está envolvido ou para sua situação — origem, deslocamento, no Brasil -);

- ou se entra pelo acontecimento (também haveria um quadrinho, maior, dominante, pegando a tela toda e que seria a junção/justaposição dos quadrinhos dos personagens espećficos daquele fato: terremoto no Haiti; bombardeio com gás na Síria, em Aleppo; saque a supermercado em Caracas / Aqui seriam construídos aqueles efeitos visuais acima descritos);

- ou se entra pela situação (no país de origem; no percurso ao Brasil; no Brasil).

Há que se dizer também que, em vários momentos, as ideias foram discutidas, implementadas no Unity/Fungus, testadas e, então, aprovadas ou canceladas (em caso de não funcionarem a contento). Diga-se que, por vezes, as nossas limitações de programação, por falta de tempo ou mesmo por domínio incompleto do programa, acabaram sendo o fator decisivo entre as diferentes opções. Isso pode ser constatado se se comparam as descrições abaixo do que seria o esquema geral de leitura, com o que se obteve ao final. O último tópico abaixo não foi implementado e, à falta de uma estratégia computacional que colocasse esses elementos diante do leitor, optamos por metaforizar o que pretendíamos fosse realizado concretamente na leitura.

Considerando os diferentes elementos presentes em e-Imigrações, certamente as maiores limitações ocorreram no projeto de interfaces de usuário e nas animações. Dado o tema e a relação com quadrinhos, imaginamos diferentes possibilidades de movimento e efeitos visuais/sonoros que seriam grandes potencializadores da imersão do leitor; infelizmente essas ideias se mostraram complexas demais e, portanto, decidimos simplificar vários desses pontos. Portanto, muitos efeitos simples foram adotados dentro do próprio Unity, principalmente através de fades ${ }^{13}$.

Uma parte considerável de nossas primeiras conversas, uma vez definida a temática e os elementos narrativos (enredos, tipos de personagens, ambientes etc.), girou em torno justamente da entrada no espaço computacional de leitura. Alguns tópicos de discussão listados abaixo foram em parte concretizados na versão final de e-Imigrações, a exemplo dos mapas interativos e imersivos (o mapa-múndi e os mapas dos três países); outros não o foram, como os efeitos visuais e interativos específicos ao mapa de cada país. Também as sequências de navegação (exibidas no esquema gráfico abaixo que havíamos construído bem no início dos trabalhos de criação) foram totalmente modificadas, pois tiveram que ser desenvolvidas em consonância com a programação computacional que se ia realizando. Em resumo, as estratégias e as possibilidades de navegação foram sendo criadas ao mesmo tempo em que a obra ia sendo criada, em nenhum momento houve subordinação da poiesis visual e da verbal à tekhnécomputacional.

Visualmente, poderíamos talvez tentar algo como:

\# Mapa múndi (clicável em Haiti, Síria, Venezuela, com mudança de visualidade ou de som para indicar interatividade), clicando vai para:

\# Mapa de cada um dos três países, com o poema relativo à tragédia de cada um (com os poemas terremoto no Haiti; bombardeio com gás na Siria, em Aleppo; saque a supermercado em Caracas - em som ambiente e em texto; neste caso, os poemas surgiriam por algum tempo sobre o mapa, como marca d'água, permitindo a leitura, sem esconder o mapa) \# Após todo o poema ser falado, abre para o clique levando à parte narrativa, mas com efeitos de transição (o mapa do Haiti, vai tremer e se despedaçar; o da Síria vai ganhando buracos de explosão; o da Venezuela vai murchando):

\footnotetext{
${ }^{13}$ Que pode ser explicado resumidamente como o efeito de fazer uma imagem desaparecer gradualmente.
} 
\# Parte narrativa - acontecimento (vide arquivo de roteiro - cada página é lida e mudada pelo leitor; nada automático); há um menu do lado esquerdo, bem discreto, permitindo ler pulando para personagens ou situações, como indicado abaixo); na página do deslocamento, vai aparecer o mapa múndi com a sequência automática de poemas (em som e em marca d'água) para cada país por onde o personagem passa; a seguir, entra na página do Brasil.

\section{PRIMEIRA TELA}
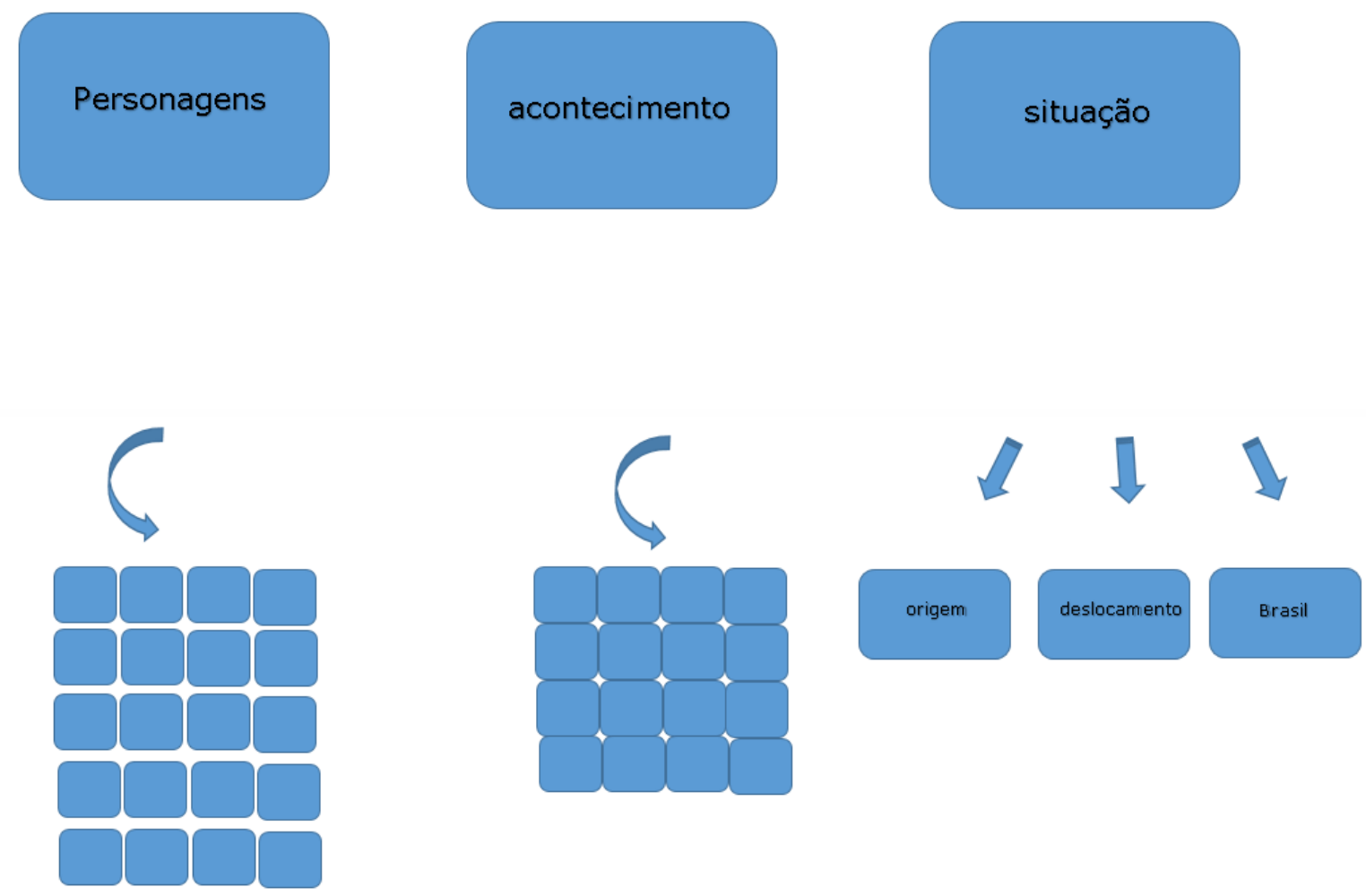

\# Brasil: colagem dinâmica com imagens (fotos, vídeos, desenhos) de violência e intolerância contra imigrantes no Brasil (quebrando a linguagem tradicional da HQ), com poema rolando apenas em áudio.

Como havíamos definido que a estrutura do enredo se iniciaria com os três países de imigrantes e concluiria no Brasil, percebemos um diálogo fortíssimo entre o deslocamento forçado dos imigrantes e a ideia de impossibilidade de retorno que, evidenciada pelo sentido das narrativas, seria extensível aos quadrinhos e poemas. Ou seja, o leitor entraria em contato com a história de emigração daquele país, acompanharia a viagem dos seus personagens ao Brasil e, retornando ao mapamúndi, enxergaria o desenho do país, os quadrinhos e os poemas no mapa: esse impacto é permanente e impossibilita o retorno ao país (e à sua história) naquela sessão de leitura.

No caso de e-Imigrações, essa relação entre estrutura narrativa e interface de navegação nos pareceu demonstrar mais potencial do que uma experiência não-linear ancorada em menus de personagens, acontecimentos e situações. O tempo de leitura de quase todos os poemas é controlado pelo clique do leitor, porém, o efeito gerado com essa decisão pode frustrar leitores que queiram retornar momentaneamente a uma página ou poema específico, principalmente quando a câmera se 
movimenta automaticamente, como é o caso das três viagens ao Brasil. Por outro lado, caso surja efeito, o leitor pode estabelecer uma relação direta entre a sensação de euforia e falta de controle com a história narrada.

\section{Consideraçôes finais}

Se já existe muita dificuldade em estabelecer gêneros ou tipos dentro das literaturas digitais, ainda seria mais difícil (senão impossível) falar em procedimentos-padrão para seus criadores. Sem querer, evidentemente, estabelecer uma sistemática de criação a ser reproduzida por outros artistas, nosso propósito com este artigo foi expor algo do que fizemos nos bastidores de nossa criação literária digital específica.

$\mathrm{Na}$ criação tradicional, impossibilitados de acompanhar o fluxo de consciência do escritor, os críticos devem se contentar com referências e indícios indiretos nos originais ou nas provas (quando existem): palavras substituídas, trechos cortados, emprego de diferentes tintas, alterações nas letras manuscritas ou nas fontes de datiloscritos etc. Nesse caso, algo próximo de bastidores são os elementos em torno dos quais se organiza a vida intelectual e literária dos escritores: cartas, documentos oficiais, testemunhos de contemporâneos etc. É evidente que, nas literaturas digitais, ocorre também o fluxo da consciência criativa, mas de forma ainda mais complexa (se for possível!) quando temos não um artista individual, mas um grupo de criadores, como é o caso da nossa e-Imigrações. Nesse caso, se não há como adentrar na intimidade de cada artista, é possível analisar as anotações que, frequentemente, são feitas durante o processo de criação, mecanismo essencial para criações em grupo. De outro lado, o estudo da genética dessas obras digitais representa um desafio talvez insuperável, justamente pela falta de um original a partir de que seriam produzidas as cópias para os leitores. Contudo, novamente aí, as anotações (como é o caso dos nossos arquivos compartilhados) podem representar algo que se aproximaria, ainda que de longe, dos originais, desde que o leitor faça um esforço enorme (ainda que sempre insuficiente) para entender e figurar o que poderia ter sido a obra literária digital, se esse ou aquele propósito tivesse chegado a bom termo. É o que esperamos seja feito pelos leitores deste artigo, que se deixem levar por essa segunda leitura de e-Imigrações, pelo que é essa nossa criação, mas também pelo que poderia ter sido.

\section{Referências bibliográficas}

DUARTE, RAFAEL SOARES. “A página infinita: leitura de algumas possibilidades narrativas nas Webcomics”. In: FREITAS, Deise J. T. de; DUARTE, Rafael Soares [org.]. Literaturas entre o digital e o analógico. Teresina: Edufpi, 2013, pp.2939.

DUARTE, RAFAel SoAREs. “Uso de elementos verbo-visuais analógicos na criação de poemas digitais”. Texto Digital. v. 14 n. 2 (2018).

LUIZ dOs SANTOS, AlCKMAR. “Como criações literárias digitais põem em diálogo a poética e a tecnologia”. FRONTEIRAZ. , v.18, p.17 - 29, 2017.

LUIZ DOS SANTOS, AlCKMAR. “Novos processos de criação literária”. Revista da ANPOLL (Online)., v.1, p.77 - 98, 2014.

LUIZ DOS SANTOS, ALCKMAR. "Quelques questions concernant les genres, à partir de l'actuelle littérature numérique brésilienne". In: TOMICHE, Anne. Le Comparatisme comme approche critique Comparative Literature as a Critical Approach. Littérature, science, savoirs et technologie / Literature, Knowledge, Science and Technology. Tomo 6. Paris: Garnier, 2017, pp. 331-345. 
revista de crítica genética

Luiz dos Santos, Alckmar. "Roteiros de uma poética: A derrubada do Sarrià". DATJournal Design Art and Technology. , v.2, p.55- 63, 2017.

LUIZ Dos SANTOS, AlCKMAR. "The cosmonaut: A Digital Creation”. MATERIALIDADES DA LITERATURA, v.6.2, p.231 - 245, 2018.

Spiegelman, ART. “Maus”. Raw Magazine. New York: Penguim Books, 1980-1991. 